\title{
Corrosion Performance of Carbon Steel in Micelle-containing Cement Extract
}

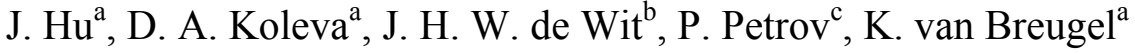 \\ ${ }^{\mathrm{ab}}$ Deft University of Technology, The Netherlands \\ ${ }^{a}$ Faculty of Civil Engineering and Geosciences, Materials \& Environment, $2628 \mathrm{CN}$ Delft \\ ${ }^{\mathrm{b}}$ Faculty $3 \mathrm{mE}$, Dep. Surfaces \& Interfaces, 2628 CD Delft \\ ${ }^{c}$ Bulgarian Academy of Sciences, Institute of Polymers, Sofia, Bulgaria
}

This study presents the results from a preliminary investigation on the corrosion behavior of low carbon steel in cement extract (CE) in the presence of very low concentration polymeric nanoaggregates $\left(\mathrm{PEO}_{113}-\mathrm{b}-\mathrm{PS}_{70}\right.$ micelles). The steel electrodes were investigated in $\mathrm{Cl}^{-}$-containing $\mathrm{CE}$ as corrosion medium, compared to chloride-free $\mathrm{CE}$ as a reference case. The results from the electrochemical measurements (Electrochemical Impedance Spectroscopy (EIS) and Potentio-dynamic Polarization (PDP)) indicate that the presence of micelles leads to increased corrosion resistance of the steel, but pronounced only at early stages (1h and $3 \mathrm{~h}$ ), whereas no significant influence was observed within longer immersion periods (5d). To some extent, this result was as expected, considering the used low concentration of micelles for this test. The surface analysis however, shows that the presence of the micelles in the cement extract, results in a more homogeneous and compact layer on the steel surface, compared to the steel immersed in the micelles-free solutions.

\section{INTRODUCTION}

It is well known that corrosion of steel reinforcement can cause reinforced concrete deterioration and thus affect civil structures durability (1-2). Logically, corrosion induced reinforced concrete degradation results in significant economic loss. For example, in U.S., the annual direct cost of bridge infrastructure corrosion was estimated to be $\$ 8.3$ billion and the indirect cost was reported to be many times higher (3).

In normal conditions, the embedded in concrete reinforcing steel is in a passive state because of the highly alkaline environment $(\mathrm{pH}=12.6-13.5)$ of the pore solution and the cement paste respectively $(4,5)$. However, corrosion can be initiated due to carbonation or chloride contamination (6). Carbonation results in a $\mathrm{pH}$ drop in the cement matrix to about 8-9, which leads to a general corrosion of on the reinforcing steel. When chlorides are present at the steel/paste interface, localized corrosion is initiated, the local $\mathrm{pH}$ can drop to even below 6 , resulting in fast corrosion propagation. This will cause accelerated damage of steel, which might result in rapid failure of reinforced concrete (7). Therefore, it is very important to develop a proper way to protect reinforcing steel from corrosion.

This work is part of a 2-years research project on the influence of admixed in reinforced concrete nano aggregates on the corrosion performance of steel in $\mathrm{Cl}^{-}$containing concrete. The main aim of the hereby reported preliminary study was to evaluate the corrosion performance of steel in micelles-containing cement extract, 
simulating the concrete pore solution. The results of this test will act as preliminary data for the ongoing investigation in reinforced mortar in the presence of the same micelles.

\section{MATERIALS AND METHODS}

Materials: Steel electrodes: low-carbon steel (ST37) electrodes with surface area of $0.65 \mathrm{~cm}^{2}$ were used for investigation. All electrodes were equally treated prior to electrochemical measurements i.e. they were grinded with no.500 to no.4000 grinding papers and polished; further, just before immersing in the relevant solution, they were cleaned with acetone.

Cement extract: the cement extract was prepared from Ordinary Portland cement OPC CEM I 42.5R and tap water by mixing in the ratio of $1: 1$; the suspension was filtrated after $24 \mathrm{~h}$ rotation and thus a simulated pore solution (CE) was obtained. The $\mathrm{pH}$ of $\mathrm{CE}$ is $12.6-12.9$.

Polymeric nano-aggregates: Polyethylene oxide (PEO) -block-polystyrene (PS) diblock copolymer $\left(\mathrm{PEO}_{113}-\mathrm{b}-\mathrm{PS}_{70}\right)$ micelles, synthesized by atom transfer radical polymerization (ATRP), employing the macroinitiator technique (8) were added to the cement extract. The stabilized micelles were received as a solution (micelles concentration of $0.5 \mathrm{~g} / \mathrm{l})$. For this study, part of the so received solution was added to cement extract (groups $\mathrm{CN}$ and $\mathrm{CNC}$ below), thus $0.0024 \mathrm{wt} \%$ of the micelles were present in both chloride-free and chloride-containing cement extract.

Sample designation: There were totally four testing solutions in this study. The samples designation is: control groups " $\mathrm{C}$ " (without micelles) and "CN" (with micelles) and corroding groups "CC" (without micelles) and "CNC" (with micelles), where $\mathrm{Cl}^{-}$was added to the $\mathrm{CE}$ in concentration of $10 \mathrm{~g} / 1$.

Methods: The electrochemical methods in this study were: electrochemical impedance spectroscopy (EIS) and potentio-dynamic polarization (PDP). A common 3electrode electrochemical cell (SCE as reference) was used and the measurements were performed at open circuit potential (OCP) for all cells. The PDP measurement was performed in the range of -0.2 to $+1.2 \mathrm{~V}$ vs OCP at scan rate $0.165 \mathrm{mV} / \mathrm{s}$. The EIS measurements were carried out in the frequency range of $50 \mathrm{kHz}$ to $10 \mathrm{mHz}$ by superimposing an ac voltage of $10 \mathrm{mV}$. The used equipment was EcoChemie AutolabPotentiostat PGSTAT30, combined with FRA2 module, using GPES and FRA interface.

Relevant to the morphological aspect of the product layers, formed on the steel surface in each medium, images of the specimens were obtained by scanning electronic microscopy (SEM), using environmental SEM (ESEM Philips XL30). The chemical composition and distribution of products, associated with corrosion (for corroding groups) and/or passivation (for control groups), were determined by XPS (not hereby reported) and energy dispersive X-ray analysis (EDX).

\section{RESULTS AND DISCUSSION}

\section{Micelles Identification}

The $\mathrm{PEO}_{113}-\mathrm{b}-\mathrm{PS}_{70}$ micelles were previously identified by TEM (8); hereby performed was a dynamic light scattering (DLS) measurement for determining the hydrodynamic radius of the micelles in the as received solution, shown in Fig.1. The results of the DLS measurement show an apparent hydrodynamic radius of $50 \mathrm{~nm}$. 


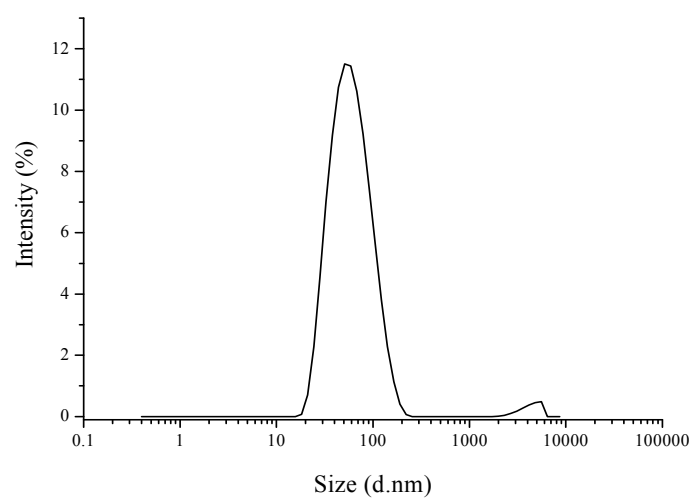

Fig.1 Dynamic light scattering (DLS) of the micelles

\section{Open circuit potential (OCP) mapping}

In general, open circuit potential (OCP) mapping determines the time to corrosion initiation. In chloride containing medium, corrosion initiation is due to the passive layer breakdown on the steel surface i.e. localized corrosion. For reinforced concrete and model pore solution respectively, the steel surface is considered passive if OCP is equal or more anodic than $-270 \mathrm{mV}$ (9-11). Fig.2 shows the OCP evolution for the steel electrodes in the testing solutions (readings are the average value of 3 samples per condition). The micelles did not significantly influence the OCP of the steel in the control groups (Groups "C" and "CN"); both groups showed OCP values more anodic than $-270 \mathrm{mV}$ i.e. a stable passive layer formed on the steel surface in chloride-free cement extracts (with and without micelles). For corroding groups, a clear positive effect in terms of more anodic potential was observed from the steel immersed in the micellescontaining cement extract (Group "CNC"), but only at earlier stages (1h and $3 \mathrm{~h}$ ). When the immersion continued, there was no obvious difference in OCP. The result indicates that the presence of micelles in $\mathrm{Cl}^{-}$-containing cement extract causes delay in corrosion initiation on the steel surface.

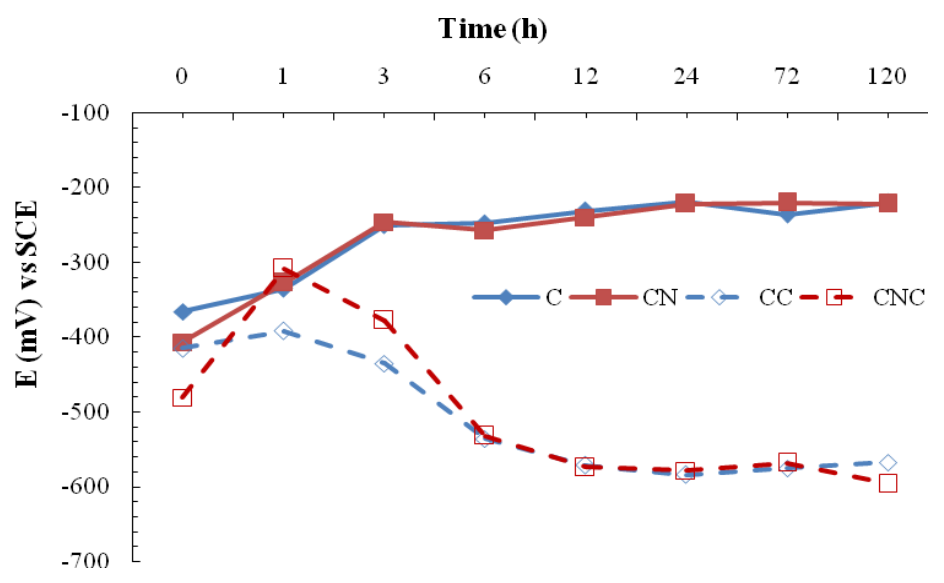

Fig.2 OCP readings of steels for all studied conditions

Electrochemical impedance spectroscopy (EIS)

Electrochemical impedance spectroscopy (EIS) is a widely applied electrochemical technique for studying the corrosion performance of steel in both reinforced concrete and in simulated pore solution (12-16). Fig.3 depicts the EIS response in Nyquist and Bode format of the steel in cement extract (micelle-free and micelle-containing solutions) in both control $(\mathrm{C}$ and $\mathrm{CN})$ and corroding $(\mathrm{CC}$ and $\mathrm{CNC}$ ) specimens. Fig.3a) presents the 
response at time interval $1 \mathrm{~h}$, Fig. $3 \mathrm{~b}$ ) depicts the response at the end of the test - time interval of $24 \mathrm{~h}$. Table 1 gives the summarized values after fitting the experimental response.
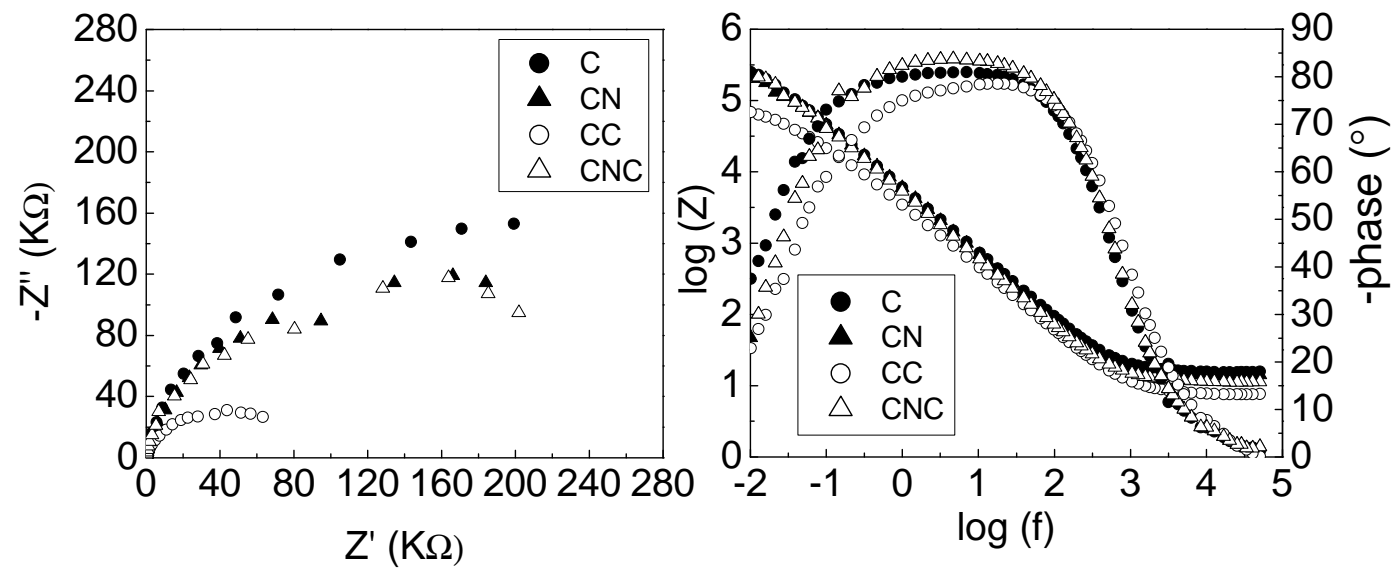

(a) $1 \mathrm{~h}$
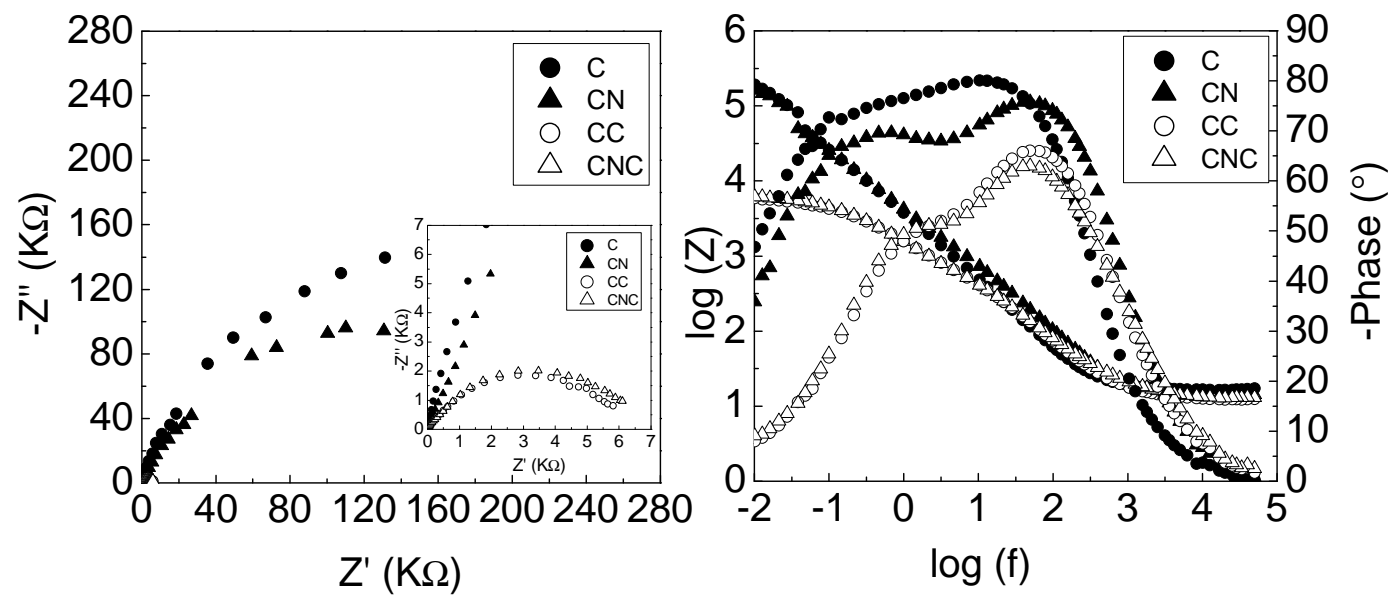

(b) $24 \mathrm{~h}$

Fig.3 EIS response in Nyquist and Bode format for steel in CE solutions (a) 1h, (b) 24h

Table 1 Best fit parameters from experimental EIS results in cement extract. Equivalent el. circuits (one or two time constants): $\mathrm{R}_{\mathrm{el}}\left(\mathrm{Q}_{\mathrm{f}} \mathrm{R}_{\mathrm{ct}}\right)$ or $\mathrm{R}_{\mathrm{el}}\left(\mathrm{C}_{\mathrm{pr} . \mathrm{l}} \mathrm{R}_{\mathrm{pr} .1}\right)\left(\mathrm{Q}_{\mathrm{f}} \mathrm{R}_{\mathrm{ct}}\right) ; \mathrm{Rel} \sim 10-15 \mathrm{Ohm}$

\begin{tabular}{|c|c|c|c|c|c|c|c|c|}
\hline $\begin{array}{c}\text { Time } \\
\text { interval }\end{array}$ & $\begin{array}{c}R_{p r . l} \\
k \Omega . m^{2}\end{array}$ & $\begin{array}{c}Y_{0,}, Q_{p r .}, \\
1 / \Omega \times 10^{-5}\end{array}$ & $n$ & $\begin{array}{c}R_{c t} \\
k \Omega . \mathrm{cm}^{2}\end{array}$ & $\begin{array}{c}Y_{0,}, Q_{f} \\
1 / \Omega \times 10^{-5}\end{array}$ & $n$ & $\begin{array}{c}R_{p} \\
\mathrm{k} \Omega . \mathrm{cm}^{2}\end{array}$ & $\begin{array}{c}R_{p} \\
k \Omega . \mathrm{cm}^{2}(P D)\end{array}$ \\
\hline \multicolumn{9}{|c|}{ Group C (control, micelle free) } \\
\hline 1h & & & & 189.41 & 3.10 & 0.9119 & 189 & 186 \\
\hline $24 \mathrm{~h}$ & 0.49 & 2.72 & 0.8643 & 186.56 & 2.24 & 0.9179 & 188 & 182 \\
\hline \multicolumn{9}{|c|}{ Group CN (control, micelle containing) } \\
\hline $1 \mathrm{~h}$ & & & & 133.19 & 3.15 & 0.9228 & 133 & 143 \\
\hline $24 \mathrm{~h}$ & 0.27 & 4.76 & 0.9772 & 133.25 & 1.18 & 0.9677 & 134 & 101 \\
\hline \multicolumn{9}{|c|}{ Group CC (corroding, micelle free) } \\
\hline $1 \mathrm{~h}$ & & & & 47.23 & 5.30 & 0.8771 & 47 & 58 \\
\hline $24 \mathrm{~h}$ & 0.15 & 10.92 & 0.7590 & 3.69 & 6.54 & 0.9839 & 4 & 5 \\
\hline \multicolumn{9}{|c|}{ Group CNC (corroding, micelle containing) } \\
\hline $1 \mathrm{~h}$ & & & & 118.56 & 3.30 & 0.9395 & 119 & 114 \\
\hline $24 \mathrm{~h}$ & 0.10 & 5.94 & 0.7212 & 4.18 & 5.51 & 0.9981 & 4 & 5 \\
\hline
\end{tabular}


The used equivalent circuits contained 1 time constant only (in series with the electrolyte resistance) for the $1 \mathrm{~h}$ response (i.e. $\mathrm{R}_{\mathrm{el}}\left(\mathrm{Q}_{\mathrm{f}} \mathrm{R}_{\mathrm{ct}}\right)$ ) and two time constants for the $24 \mathrm{~h}$ response (i.e. $\mathrm{R}_{\mathrm{el}}\left(\mathrm{C}_{\mathrm{pr.} .1} \mathrm{R}_{\mathrm{pr} .1}\right)\left(\mathrm{Q}_{\mathrm{f}} \mathrm{R}_{\mathrm{ct}}\right)$ ). The physical meaning of the involved parameters is as follows: $R_{e l}$ - electrolyte resistance; $Q_{f}$ and $R_{c t}-$ pseudo capacitance and charge transfer resistance, related to the electrochemical reaction on the steel surface; $\mathrm{C}_{\text {pr.l }}$ and $\mathrm{R}_{\text {pr.1. }}$ - capacitance and resistance of the product layer on the steel surface.

As seen from Fig 3, the control groups $\mathrm{C}$ and $\mathrm{CN}$ exhibit high corrosion resistance (very high magnitude of $|\mathrm{Z}|$ for both groups), which indicate that a stable passive layer was formed on the steel surface in chloride-free environment (as expected). The micelles caused no significant influence to the observed corrosion resistance. For the corroding groups $\mathrm{CC}$ and $\mathrm{CNC}$, the data derived from EIS measurement provide evidence for the initially enhanced corrosion resistance of steel in micelles-containing solutions: at the early immersion stages, the value of $\mathrm{Z}$ was higher for the micelles-containing sample (close to the control cases) compared to the micelles-free sample, denoting higher corrosion resistance of steel for the micelles containing sample. When the immersion continued, at the immersion time of $24 \mathrm{~h}$, there was no obvious difference of corrosion resistance. Although higher $\mathrm{R}_{\mathrm{ct}}$ resistance was derived for CNC specimens, the $\mathrm{R}_{\mathrm{p}}$ values are similar for specimens $\mathrm{CC}$ and $\mathrm{CNC}$ at the stage of $24 \mathrm{~h}$ (Table 1). The results indicate that the micelles can result in a significant corrosion resistance improvement of steel mainly at early immersion stages.

\section{Potentio-dynamic polarization (PDP)}

The data derived from EIS measurement are supported by potentio-dynamic polarization (PDP) measurements in the studied solutions. As seen from Fig. 4, the specimens immersed in the chloride-free solutions (Group "C" and "CN") depict similar behavior with external polarization. For the specimens immersed in chloride-containing solutions (Group "CC" and "CNC"), the data showed a pronounced positive effect of the micelles at early stages (Fig.4, (a) 1h), evidenced by more anodic corrosion potential, lower corrosion and anodic current densities for the micelles-containing specimen (actually similar to the control groups). When the immersion continued, there was no significant influence of the micelles (Fig.4, (b) 24h), however, for the micelles containing specimen, the corrosion potential was still slightly more anodic and the anodic current density was slightly lower, compared to the micelles-free specimen.

Fig. 5 shows the summarized $R_{p}$ values (as also given in Table 1, in comparison to the $R_{p}$ values, derived from EIS), derived from potentio-dynamic polarization. For the control groups, the $R_{p}$ was quite high ((in the range of $100-200 \mathrm{~K} \Omega . \mathrm{cm}^{2}$ ) which indicates passivity. For the corroding groups, the same trend as within EIS measurements was observed: The $R_{p}$ value of steel in micelles-containing solution was higher than that in micelles-free solution at early periods, such as $1 \mathrm{~h}$ and $3 \mathrm{~h}$. Further, similar $\mathrm{R}_{\mathrm{p}}$ values for both $\mathrm{CC}$ and $\mathrm{CNC}$ were recorded. Based on all electrochemical measurements, it can be indicated that the micelles are able to increase the corrosion resistance of the steel in cement extract. However, an obvious improvement only appears at early stages, which is as expected, considering the used low concentration of micelles for this test. 


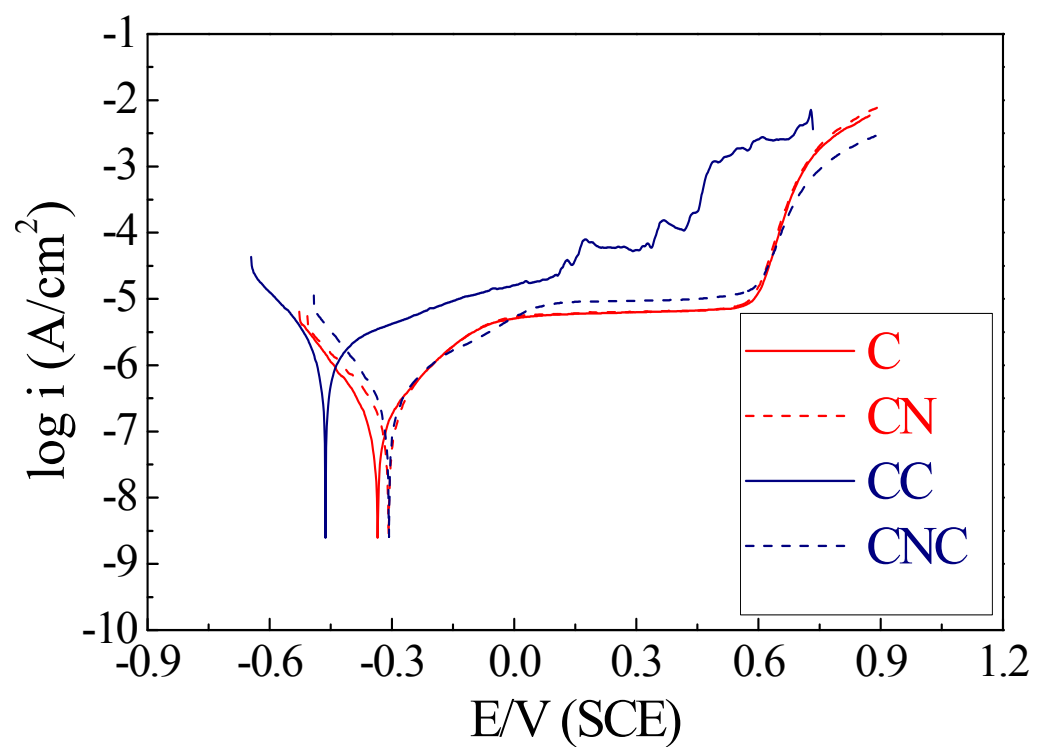

(a) $1 \mathrm{~h}$

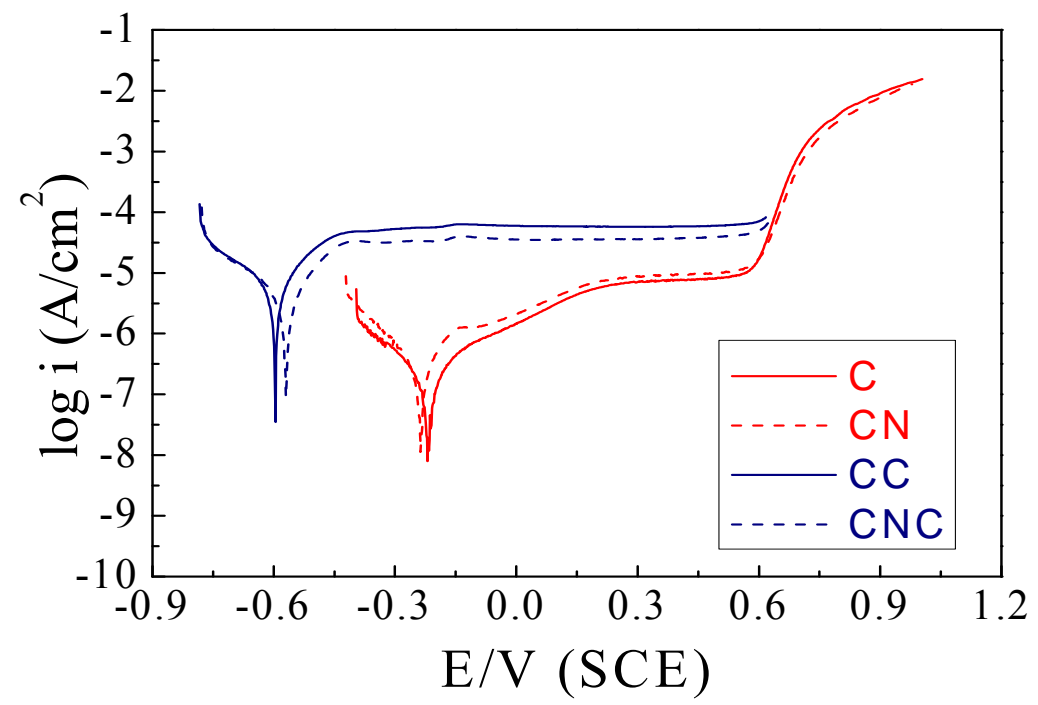

(b) $24 \mathrm{~h}$

Fig.4 Potentio-dynamic polarization of steel in CE solutions (a) 1h, (b) $24 \mathrm{~h}$

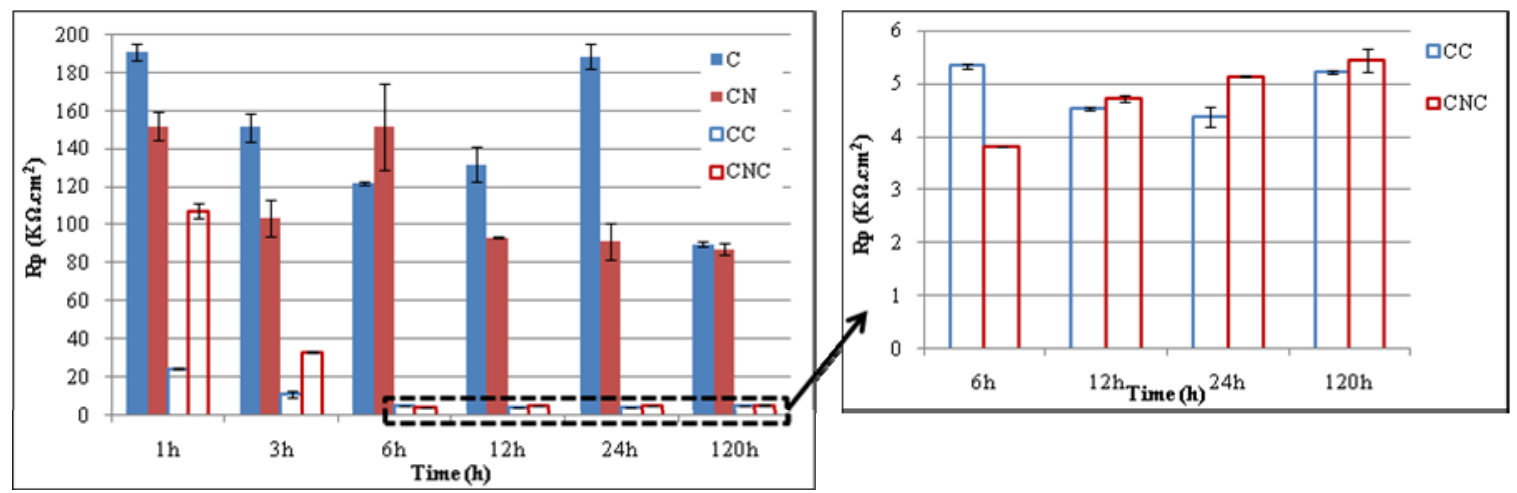

Fig 5 Rp values of steel which are derived from PDP 


\section{Morphology}

Fig. 6 shows the morphology of the steel surface after immersion in cement extract for $1 \mathrm{~h}$ and $120 \mathrm{~h}$ (no significant difference between $1 \mathrm{~h}$ and earlier intervals as 3h, 6h, 12 and $24 \mathrm{~h}$ was observed). For the control groups (Fig. 6 (a) and top row in Fig. 6 (c)), similar morphology (and composition, Table 2) were recorded.

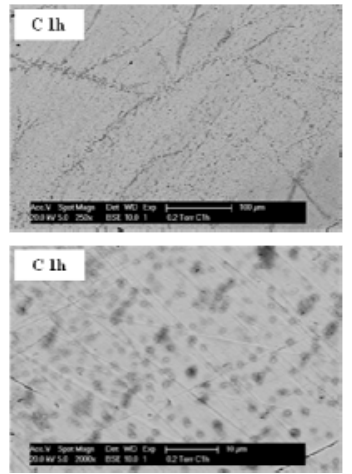

(a) $1 \mathrm{~h}$ Control samples
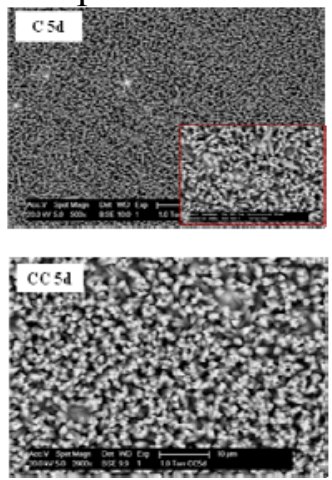

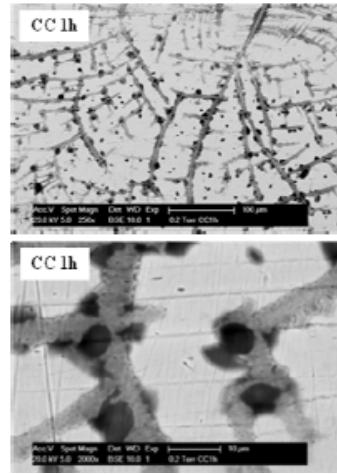

(b) $1 \mathrm{~h}$ Corroding samples
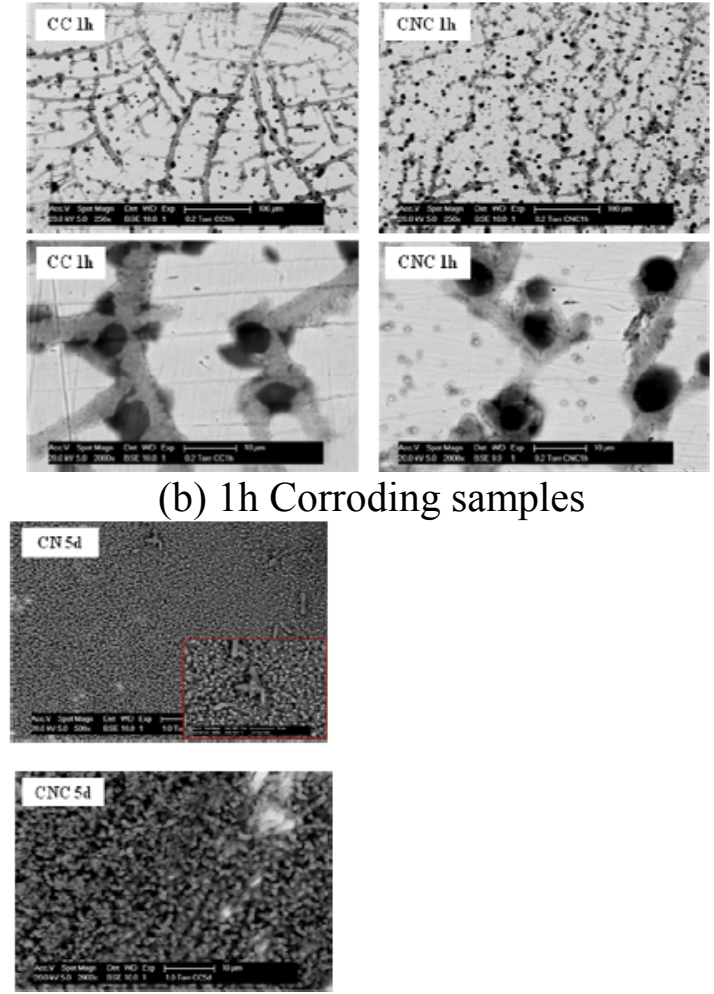

(c) $120 \mathrm{~h}$

Fig.6 Morphology of steel surface in CE solutions at $1 \mathrm{~h}$ and $120 \mathrm{~h}$ obtained by ESEM

Table 2 Summarized data from EDAX analysis of steel surface (1h)

\begin{tabular}{l|r|r|r|r}
\hline Elements & C (wt \%) & CN (wt \%) & CC (wt \%) & CNC (wt \%) \\
\hline $\mathrm{Na}$ & 2.29 & 2.22 & 8.57 & 7.89 \\
\hline $\mathrm{Al}$ & 0.7 & 0.25 & 0.27 & 0.27 \\
\hline $\mathrm{Si}$ & 0.8 & 0.14 & 0.31 & 0.31 \\
\hline $\mathrm{S}$ & 0.7 & 0.43 & 0.45 & 0.33 \\
\hline $\mathrm{Cl}$ & 0.63 & 0.39 & 2.88 & 1.9 \\
\hline $\mathrm{K}$ & 1.34 & 1.55 & 1.37 & 1.09 \\
\hline $\mathrm{Ca}$ & 0.64 & 0.55 & 0.37 & 0.43 \\
\hline $\mathrm{Fe}$ & 81.19 & 79.02 & 77.12 & 77.43 \\
\hline
\end{tabular}

For the corroding groups (Fig. 6 (b) and bottom row in Fig. 6 (c)), in addition to product layer, formed in the cement extract, as well as well visible "pitting" corrosion (for both $\mathrm{CC}$ and $\mathrm{CNC}$ ), micelles, attracted to the steel surface in specimen $\mathrm{CNC}$, can be observed at higher magnification (bottom row in Fig.6 (b)). The presence of micelles on the steel surface would be expected to improve at least the barrier properties of the formed layer. However, this effect only appeared at early immersion intervals. Within longer immersion times, there is no apparent difference in the appearance of the product layers as observed by ESEM (Fig.6 (c)). The results from EDAX (most relevant elements) 
are summarized in Table 2. The EDAX results show that at $1 \mathrm{~h}$ time interval, more carbon was detected on micelles containing sample (for control groups, the carbon content of the micelles-containing specimen was $9.26 \mathrm{wt} \%$, compared to $6.69 \mathrm{wt} \%$ for micelles-free specimen) which indicates that the micelles are attracted on the steel surface. Besides, chloride concentration was lower for the micelles containing sample (CNC) which means better properties of the product layer and an increased corrosion resistance of the steel.

\section{CONCLUSIONS}

A preliminary study on the corrosion behavior of low-carbon steel in cement extract (CE) in the presence of polymeric nano-aggregates $\left(\mathrm{PEO}_{113}-\mathrm{b}-\mathrm{PS}_{70}\right.$ micelles $)$ is reported in this work. The electrochemical tests indicate that a very low concentration of micelles $(0.0024 \mathrm{~g} / \mathrm{l})$ is able to increase the corrosion resistance of the steel in chloride-containing cement extract. However, the effect only appears at early immersion time which is to some extent as expected due to the very low concentration of micelles in the solution. On the other hand, surface analysis indicates that the micelles are attracted to the steel surface and apparently can improve the barrier effects of the product layers at early time intervals. On-going is the investigation on determining the optimum concentrations and micelles type for improved steel corrosion resistance in model solutions and reinforced cement-bases materials.

\section{REFERENCES}

1. C. L. Page, K. W. J. Treadaway, and P. B. Bamforth. Corrosion of Reinforcement in Concrete, Elsevier Applied Science, London (1990).

2. N. S. Berke, V. Chaker, and D. Whiting, Corrosion of Steel in Concrete, ASTM STP 1065, ASTM, Philadelphia, PA (1990).

3. S.D. Cramer, B.S. Covino, S.J. Bullanrd, G.R. Holcomb, J.H.Russell, M. Zimolekmoroz, Y.P. Voramo, J.T. Bulter, F.J. Nelson,N.G. Thompson, Prevention of chlorideinduced corrosion damage to bridges, ISIJ Int. 42 1376-1385 (2002).

4. M. Pourbaix, Atlas of Electrochemical Equilibria in Aqueous Solutions, NACECEBELCOR, Houston, TX, (1974).

5. Gadadhar Sahoo, R. Balasubramaniam. Corrosion Science 50 131-143v(2008).

6. L. J. Parrot, A Review of Carbonation in Reinforced Concrete, British Cement Association Report C/i-0987 (1987).

7. M.M. Mennucci, E.P. Banczek, P.R.P. Rodrigues, I. Costa. Cement \& Concrete Composites 31 418-424 (2009).

8. Petrov P., Bozukov M. et al J. Mater. Chem, 15: 1481 (2005).

9. Alonso C., Castellote M., Andrade C., Electrochim. Acta ,47, 3469 (2002)

10. Li L., Sagüés A.A., Corrosion 57, 19 (2001)

11. Miranda J.M., González J.A., Cobo A., Otero E., Corros. Sci., 48, 2172 (2006)

12. J. R. MacDonald, Impedance Spectroscopy, Emphasizing Solid Materials and 
Systems, Wiley, New York (1987).

13. DA Koleva, J. H. W. de Wit, K van Breugel, E van Westing. J Electrochem Soc 154(4) 52-61 (2007).

14. Jinxia $\mathrm{Xu}$, Linhua Jiang, Jingxiang Wang. Construction and Building Materials 23 1902-1908 (2009).

15. Andrade C., Keddam M., Nóvoa X. R., Pérez M.C., Rangel C. M. and Takenouti H., Electrochim. Acta, 46, 3905 (2001).

16. Cabeza M., Merino P., Miranda A., Nóvoa X. R. and Sanchez I., Cem.Concr.Res, 32, 881 (2002) 